\title{
Pollen Morphology and Pollen Fertility Estimation of Three Medicinal Plant Species of Hypericum L. from Kaghan Valley, Northern Pakistan
}

\author{
Paras Mazari1,2*, Quanru Liu', Mir Ajab Khan², Sehrish Sadia1, Latif Ahmad1 \\ ${ }^{1}$ College of Life Sciences, Beijing Normal University, Beijing, China \\ ${ }^{2}$ Department of Plant Sciences, Quaid-i-Azam University, Islamabad, Pakistan \\ Email: *parasmazari@gmail.com
}

How to cite this paper: Mazari, P., Liu, Q.R., Khan, M.A., Sadia, S. and Ahmad, L. (2017) Pollen Morphology and Pollen Fertility Estimation of Three Medicinal Plant Species of Hypericum L. from Kaghan Valley, Northern Pakistan. American Journal of Plant Sciences, 8, 3073-3083. https://doi.org/10.4236/ajps.2017.812207

Received: September 20, 2017 Accepted: November 14, 2017 Published: November 17, 2017

Copyright (c) 2017 by authors and Scientific Research Publishing Inc. This work is licensed under the Creative Commons Attribution International License (CC BY 4.0).

http://creativecommons.org/licenses/by/4.0/

\begin{abstract}
Pollen morphology \& pollen fertility estimation of three medicinal species belonging to genus Hypericum L. from flora of Kaghan valley, Northern Pakistan was investigated by light and scanning electron microscopy for the first time. The species are Hypericum elodeoides Choisy in, Hypericum oblongifolium Choisy, and Hypericum perforatum L. Pollen morphological characteristics with considerable variation are provided for these taxa. Among the studied taxa, the pollen grains were 3-4 colporate type and the largest pollen size was found in $H$. oblongifolium in polar view $23.0 \mu \mathrm{m}$ and in equatorial view was $25.35 \mu \mathrm{m}$. The smallest pollen was of $H$. elodeoides in polar view which was $19.91 \mu \mathrm{m}$ and in equatorial view was observed $12.53 \mu \mathrm{m}$ in $H$. perforatum. The shape of the all pollen grain was circular to semi-angular in polar view, however in equatorial view the shape of the grains was oblate-spheroidal, in $H$. elodeoides, and $H$. oblongifolium while prolate in $H$. perforatum. Exine sculpturing was observed by scanning electron microscopy which showed foveolate sculpturing in $H$. elodeoides, reticulate in $H$. oblongifolium and scabrate in $H$. perforatum. Pollen fertility estimation ranged from $82.66 \%$ to $90.90 \%$ which shows that flora of selected species is well established.
\end{abstract}

\section{Keywords}

Hypericum, Pollen Fertility, Kaghan Valley, Pollen Morphology, SEM

\section{Introduction}

The flowering plant genus; Hypericum L. is one of the 100 large angiosperm genera and the largest genus of nine genera of the family Hypericaceae with about 
469 species occurring naturally and have been introduced to, every continent except Antarctica. Approximately $80 \%$ of the diversity of the family is within Hypericum [1] [2] [3]. Family Hypericaceae belongs to order Malpighiales and contains well-known medicinally valuable species [2] [4]. The genus Hypericum is known worldwide for its traditional and modern uses. There are variety of bioactive compounds found in many species of Hypericum, which are used pharmacologically as well as to treat many diseases like tumors, cancer, AIDS, mild depression and kidney failure etc. [2] [5] [6]. The most well-known species of the genus Hypericum is St. John's wort Hypericum perforatum which is economically important crop plant with antiviral, anticancer, antibacterial and antidepressant properties [7] [8]. Flowers of this plant are known to use for relieving body pains and tea preparation in Kaghan Valley [9].

Genus Hypericum $\mathrm{L}$ has been studied by various researchers for its taxonomic, chemotaxonomic, pharmacological, karyological, ethnobotanical aspects. However a recent phylogenetic study based on morphological characters was carried out (Nurk and Blattner, [10] while based on phylogenetic characters was studied by (Nurk [11] and Rhufel et al. [12]. Palynology of the Hypericum recently studied by Otaghvari et al. and previously have been studied by Khan, Thomas, Aytug et al., Charpin studied regarding allergic pollen), Yi, Clarke, Barros and Ramos, Martonfi et al., Meseguer and Sanmartin and Ocak et al., [6] [13]-[24] but the pollen morphology of Hypericum from Pakistan is still not known. However it has been largely studied for its medicinal properties, ethnobotanical uses, traditional knowledge and antioxidant capacity [9] [25] [26].

The knowledge of pollen morphology and taxonomy can be used as an instrument of multiple scientific researches in systematic botany, paleobotany, paleoecology, pollen analysis, aeropalynology, criminology, allergy, stratigraphic correlation of oil-bearing rocks and coal fields, drugs in the field of medicopalynology and improvement of honey in the field of mellittopalynology and copropalynology [27]. Application of pollen morphology in plant taxonomy is best evidence in the flowering plants, especially in the angiosperms. The largest variety of pollen morphology occurs among the angiospermic plants [28]. Like other disciplines pollen grains have an important part in modern issue of plant taxonomy [29].

The present investigation is based on pollen morphology and pollen fertility estimation of three medicinally important plant species of genus Hypericum studied for the first time from Pakistan.

\section{Materials \& Methods}

Study Area-The Kaghan valley covering an area of 19790.4 hectare spreads on either bank of river Kunhar, situated in the district Mansehra, Hazara division, Northern Pakistan (Figure 1). It is located between $34^{\circ}-14^{\prime}$ and $35^{\circ}-11^{\prime}$ north latitudes and $72^{\circ}-49^{\prime}$ and $74^{\circ}-08^{\prime}$ east longitude. It is bounded in the north by Batagram and Kohistan districts, in the east by Muzafarabad district of Azad 


\section{KAGHAN VALLEY}

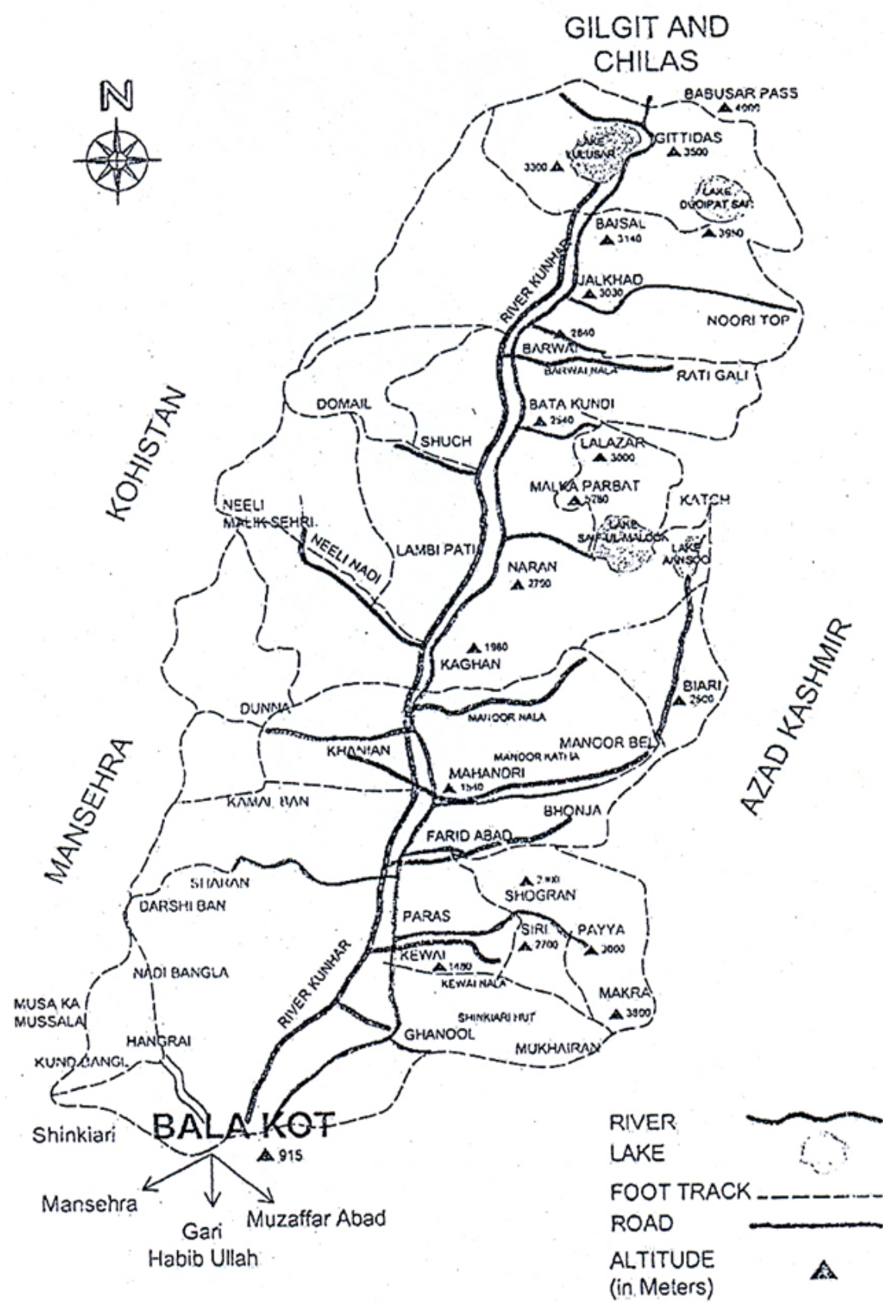

Figure 1. Map of the study area.

Jamu and Kashmir, in the south by Abbottabad and Haripur districts and in the west by Swat district [30]. The climate of the the Kaghan valley is cold in summer owing to snow clad mountains and very cold in winter Temperature ranges from $2^{\circ} \mathrm{C}-30^{\circ} \mathrm{C}$ in the district The general vegetation is of the scrub type which includes the shrubs or medium size trees [31]. There is a great variety of medicinal plants growing throughout the area which are commonly being used by the local people. 
Three medicinally important plant species of genus Hypericum L. were observed for their pollen morphology and pollen fertility estimation in the Plant Taxonomy Laboratory, Herbarium of Quaid-i-Azam University, Islamabad \& Centralized Science Laboratory University of Karachi. Pollen materials of fresh specimens were collected from flora of Kaghan Valley and used for LM and SEM.

\section{Light Microscopy (LM)}

For light microscopy slides were prepared by using glycerin jelly and safranine according to modified method of Mazari et al. [32]. The slides were prepared and observed at different magnification. The micro-graphs of these mounted materials were taken using a digital camera (Meiji CCD Model 00179048, Canada) fitted on the Lieca light microscope (DM 1000, Germany). All photographs were taken on different object lenses by using oil emulsion.

\section{Scanning Electron Microscopy (SEM)}

The pollen grains were prepared for scanning electron microscopy (SEM). Pollen grains suspended in a drop of water were directly transferred with a fine pipette to a metallic stub using double sided cello tape and coated with gold in a sputtering chamber (Ion-sputter JFC-1100). Coating was restricted to150A. The S.E.M examination was carried out on a Jeol microscope JSM-2.

\section{Pollen Fertility Estimation}

Pollen fertility percentage was calculated on the basis of staining by Glycerin jelly. The prepared slides were observed at low magnification. Glycerin jelly was used in pollen staining and prepared according to modified method of Mazari et al. [33]. Percentage of pollen fertility was calculated on the basis of staining by Glycerin jelly. The number of stained and unstained pollen grains was counted. Fully stained pollens were considered fertile while the lightly stained or unstained and deformed pollens were considered sterile. Percentage of pollen was determined by the formula: No. of total pollen/ No. of fertile pollen = Percentage Pollen fertility.

The descriptive terms for pollen morphology are used according to terminology of Erdtman), Kremp, Faegri \& Iversen, Punt et al., and Walker \& Doyle [34]-[39].

\section{Results}

The pollen morphology and pollen fertility estimation of the three selected species of Hypericum was carried out by using light and scanning electron microscopy. Micrographs of pollen grains are presented in Figure 2 and Figure 3. Findings of each species are represented in an order of local name, English name, phytogeography, flower color and season and palynomorph features. These results are summarized in Table 1. 


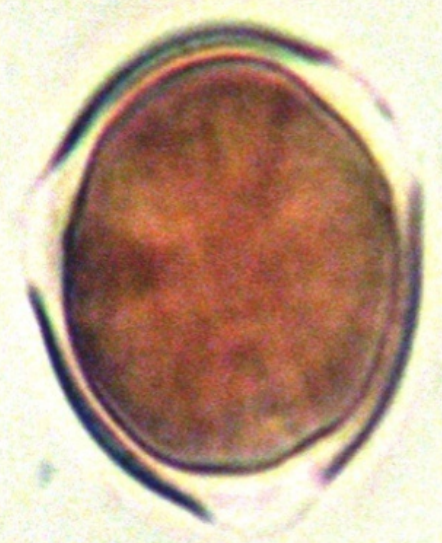

(a)

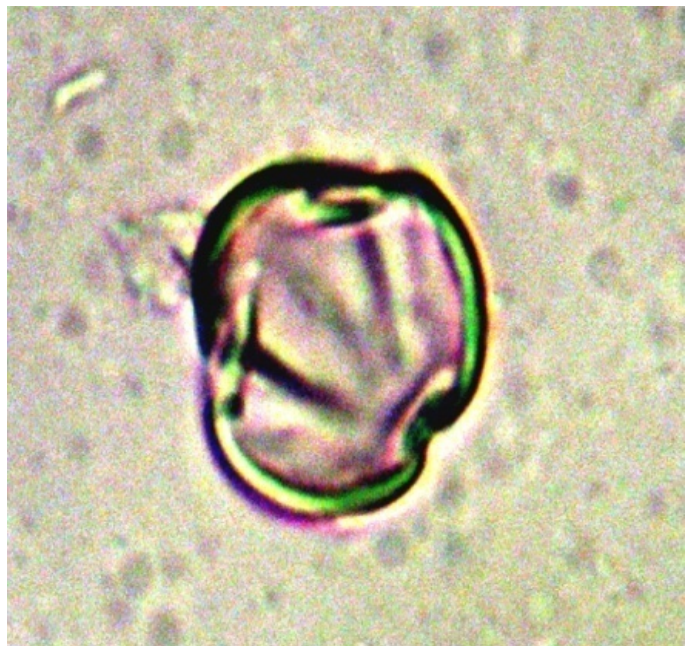

(c)

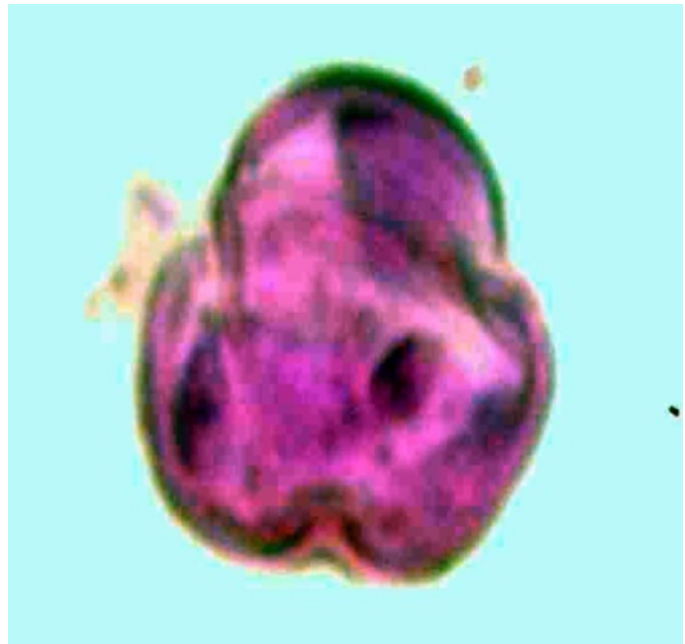

(e)

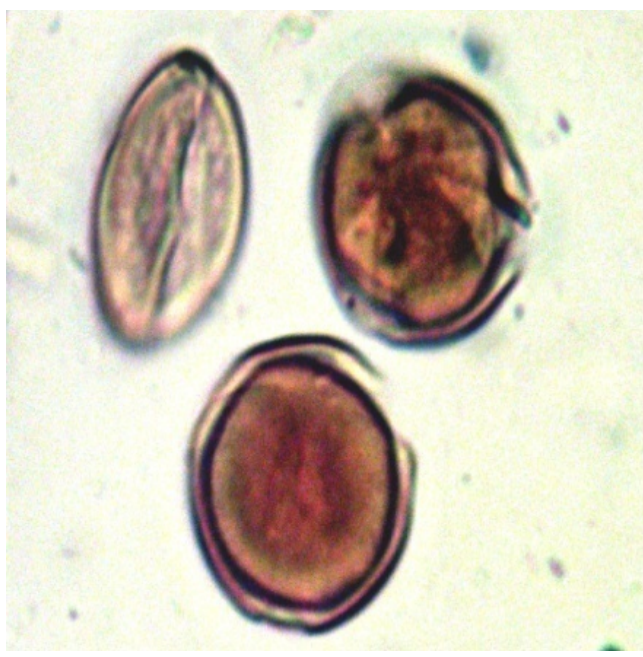

(b)

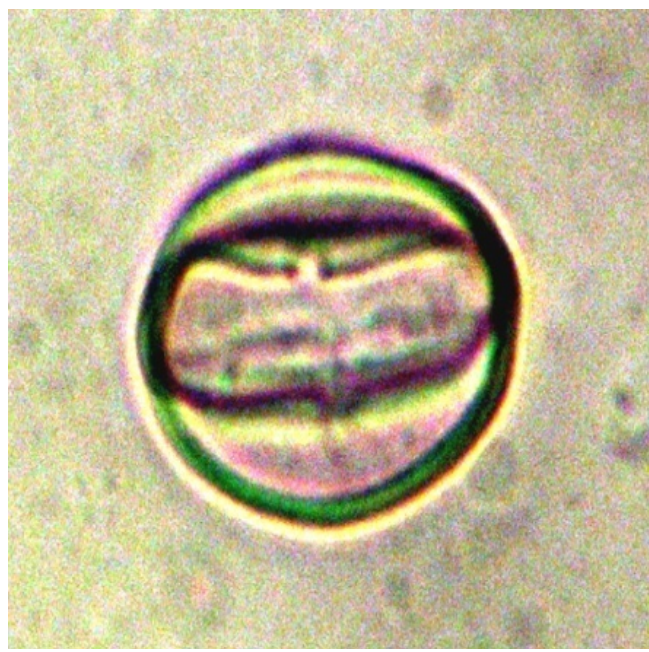

(d)

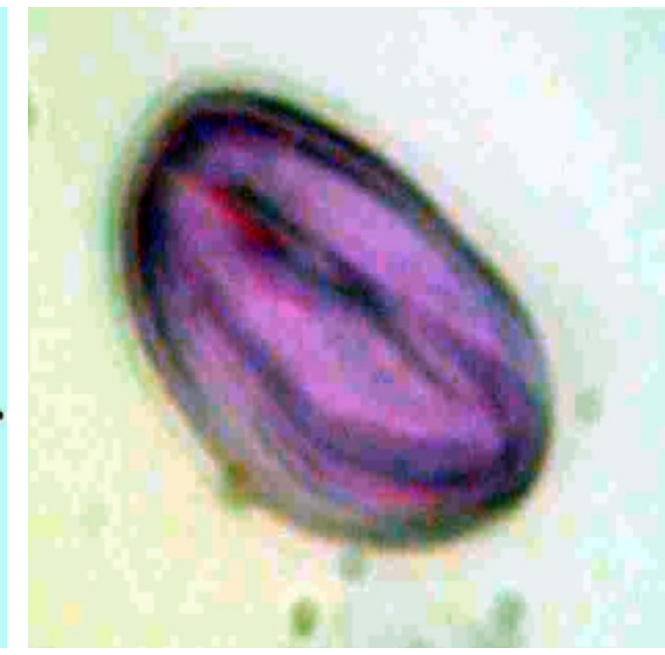

(f)

Figure 2. Light micrographs of pollen grains of Hypericum L. (a), (b): Hypericum elodeoides. Polar view, (a) (b) equatorial and polar view; (c), (d): Hypericum oblongifolium: Polar view, (c) equatorial view, (d), (e), (f): Hypericum perforatum: Polar view, (e) equatorial view, (f) (1000×). 


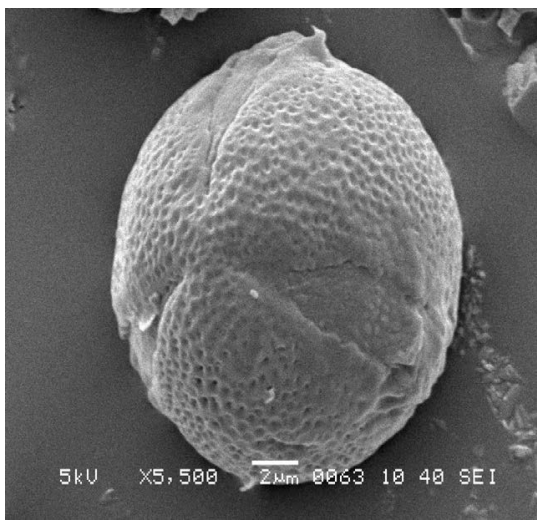

(a)

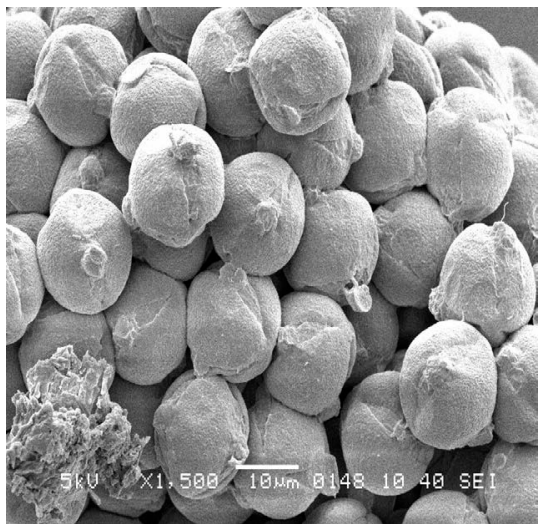

(d)

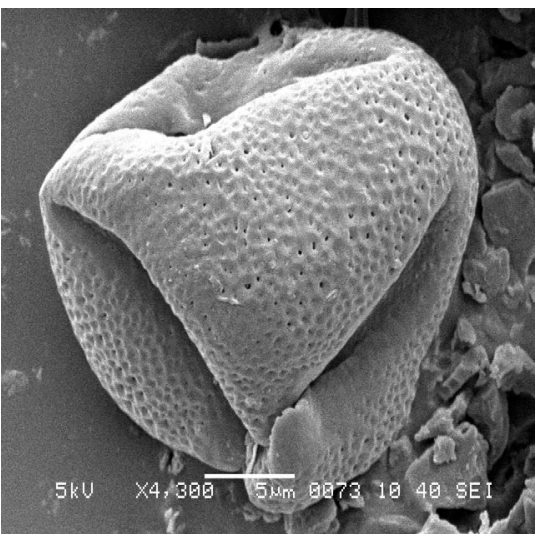

(g)

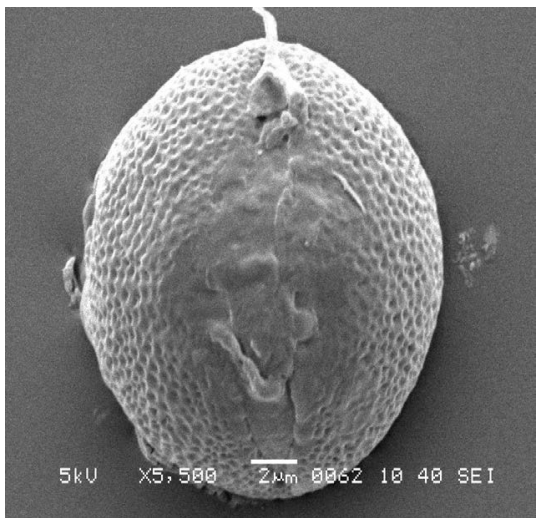

(b)

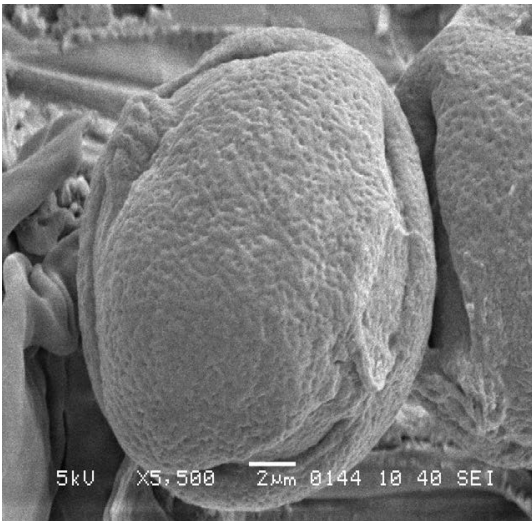

(e)

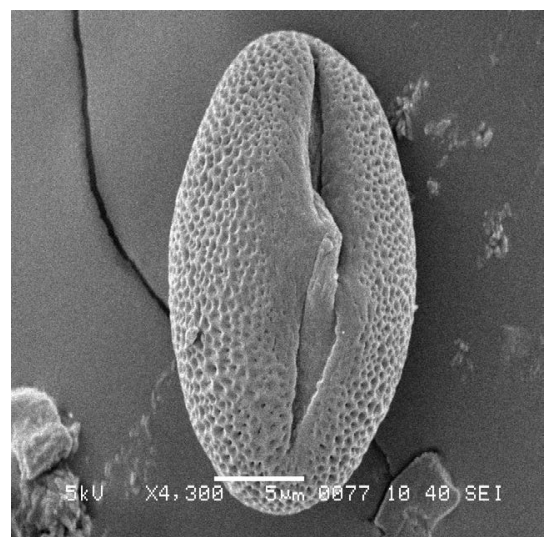

(h)

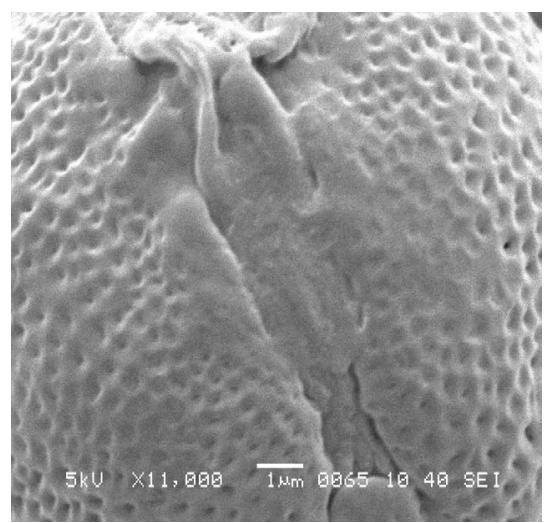

(c)

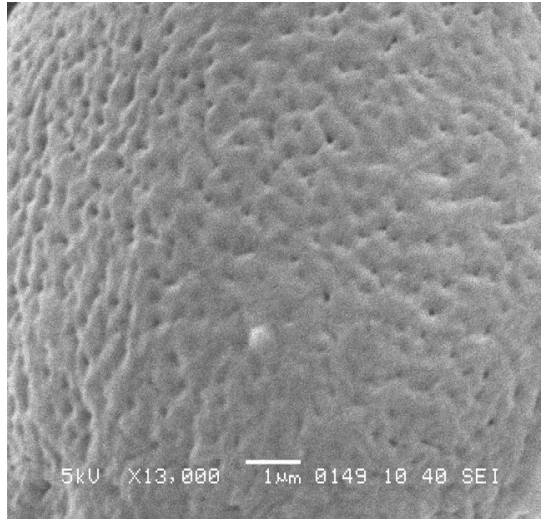

(f)

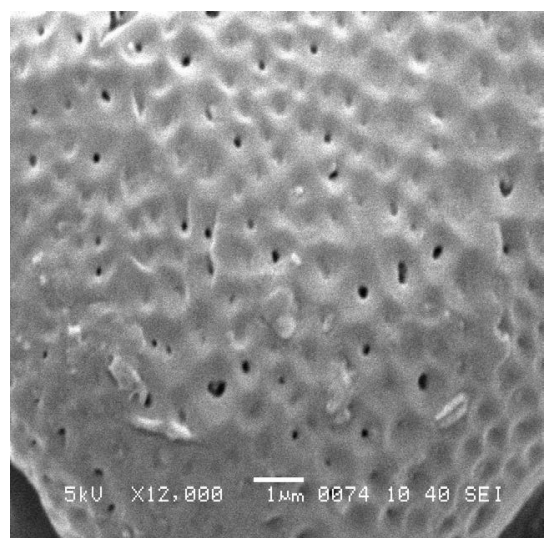

(i)

Figure 3. Scanning electron micrographs of pollen gains of Hypericum L. (a)-(c): Hypericum elodeoides: Polar view, (a) equatorial view, (b) exine sculpturing, (c) (d)-(f): Hypericum oblongifolium: Polar view in bunches, (d) equatorial view, (e) sculpturing, (f) (g)-(i): Hypericum perforatum: Polar view, (g). Equatorial view (h). Sculpturing, (i).

\subsection{Hypericum elodeoides Choisy}

Local Name: Kasni.

English Name: Marsh Stewart John's wort.

Phytogeography: It is found from Kashmir to Yunnan and Burma.

In Pakistan it is found in Basaoli, Budrawur, Gulmarg, Kashmir \& Northern areas. 
Flower color \& period: Yellow \& July-September.

Palynology: The pollen is monad, diad and tri to tetra-colporate. The shape of pollen in polar view is circular to semi-angular and in equatorial view is oblate-spheroidal (Figure 2(a), Figure 2(b)). The polar axis (P) is $19.91 \mu \mathrm{m}(17.5$ $22.5 \mu \mathrm{m})$ and equatorial diameter is $20.6 \mu \mathrm{m}(19-22.5 \mu \mathrm{m})$. P/E ratio is $0.96 \mu \mathrm{m}$. Exine thickness is $1.41 \mu \mathrm{m}(1.25-1.5 \mu \mathrm{m})$ (Table 1$)$.

Sculpturing: Foveolate with depressions less than $1 \mu \mathrm{m}$ in diameter (Figure $3(c))$.

\subsection{Hypericum oblongifolium Choisy}

Syn: $H$. cernuumRoxb., nomen

Local Name: Pinli

English Name: St. John's wort.

Phytogeography: It is found in Western Himalayas from Kurram to Nepal.

In Pakistan it is found in Kurram, lower Swat, Hazara, Malakandi, Kaghan, Nathiagali, Muree, Kashmir, Poonch.

Flower color \& period: Yellow \& March-August.

Palynology: The pollen is monad and tri-colporate. The shape of pollen in polar view is circular to semi-angular and in equatorial view is oblate-spheroidal (Figure 2(c), Figure 2(d)). The polar axis (P) is $23.0 \mu \mathrm{m}(20-27.5 \mu \mathrm{m})$ and equatorial diameter is $25.35 \mu \mathrm{m}(23.75-27.5 \mu \mathrm{m})$. P/E ratio is $0.90 \mu \mathrm{m}$. Exine thickness is $1.58 \mu \mathrm{m}(1-2 \mu \mathrm{m})$ (Table 1$)$.

Sculpturing: Lovely reticulate with diffuse lumina and muri (Table 1 and Figure 3(f)).

\subsection{Hypericum perforatum L.}

Local Name: Bilsana.

English Name: Goat weed /Tipton's weed/ Klamathweed /St. John's wort.

Phytogeography: Europe and N. Africa to W. China and N.W., India. Introduced to East Asia, America. Australasia and South Africa.

In Pakistan it is found in Kurram, Chitral, Swat, Astor, Gilgit, Balistan, Hazara, Muree Hills, Poonch \& Kashmir.

Flower color \& period: Yellow \& June to September.

Table 1. Summary of qualitative and quantitative characters of pollen of Hypericum taxa.

\begin{tabular}{|c|c|c|c|c|c|c|c|c|c|c|c|}
\hline $\begin{array}{l}\text { S. } \\
\text { No. }\end{array}$ & Species & Vouchers & Type & $\begin{array}{l}\text { Shape in } \\
\text { polar view }\end{array}$ & $\begin{array}{l}\text { Shape in } \\
\text { equatorial view }\end{array}$ & $\mathbf{P}$ & E & $\mathrm{P} / \mathrm{E}$ & $\begin{array}{l}\text { Exine } \\
\text { Thickness }\end{array}$ & $\begin{array}{c}\text { Exine } \\
\text { Ornamentation }\end{array}$ & $\begin{array}{c}\text { Pollen } \\
\text { fertility } \%\end{array}$ \\
\hline 1. & Hypericum elodoides Choisy & P08 & 3-4colporate & $\begin{array}{l}\text { circular to } \\
\text { semi-angular }\end{array}$ & Oblate-spheroidal & 19.91 & 20.6 & 0.96 & 1.41 & Foveolate & $82.66 \%$ \\
\hline 2. & $\begin{array}{l}\text { Hypericum oblongifoilum } \\
\text { Choisy }\end{array}$ & P09 & $\begin{array}{l}\text { Monad and } \\
\text { 3-colporate }\end{array}$ & $\begin{array}{l}\text { circular to } \\
\text { semi-angular }\end{array}$ & $\begin{array}{l}\text { Oblate-spheroidal } \\
\text { and spheroidal }\end{array}$ & 23.0 & 25.35 & 0.90 & 1.58 & Reticulate & $90.69 \%$ \\
\hline 3. & Hypericum perforatum $\mathrm{L}$. & P10 & $\begin{array}{c}\text { monad, } \\
\text { trilete } \\
\text { 3-colporate }\end{array}$ & $\begin{array}{l}\text { circular to } \\
\text { semi-angular }\end{array}$ & $\begin{array}{l}\text { Prolate } \\
\text { and rhomboidal }\end{array}$ & 20.78 & 12.53 & 1.65 & 1.35 & Scabrate & $90.90 \%$ \\
\hline
\end{tabular}

Note: All the measurements are in $\mu \mathrm{m}$. $(\mathrm{P}=$ Polar Diameter, $\mathrm{E}=$ Equatorial Diameter, $\mathrm{P} / \mathrm{E}$ Polar diameter divided by Equatorial diameter. 
Palynology: The pollen is monad and tricolporate. The shape of pollen in polar view is circular to semi-angular and in equatorial view is oblate, prolate and rhomboidal (Figure 2(e), Figure 2(f)). The polar axis (P) is $20.78 \mu \mathrm{m}(17.5$ - 21 $\mu \mathrm{m})$ and equatorial diameter is $12.53 \mu \mathrm{m}(17.5-38 \mu \mathrm{m})$. P/E ratio is $1.65 \mu \mathrm{m}$. Length of colpi is $4 \mu \mathrm{m}(5.75-8.25 \mu \mathrm{m})$ and width of colpi is $2.37 \mu \mathrm{m}(2.25-2.5$ $\mu \mathrm{m})$. Exine thickness is $1.35 \mu \mathrm{m}(1-2 \mu \mathrm{m})$ (Table 1$)$.

Sculpturing: Scabrate, sculpturing elements less than $1 \mu \mathrm{m}$ (Table 1 and Figure 3(i)).

Pollen fertility: Pollen fertility is valuable for the taxonomists in attempting to distinguish putative hybrids from the parent plants and is also useful to determine the degree of fertility in those plants that are grown under unfavorable conditions [40]. The pollen fertility studies have been proved helpful for recognizing wide range of variation existing within plant species and differentiating plant species within genera. Many workers have tried to correlate in vitro pollen fertility with a survival of a plant under its natural habitat [41]. Matin et al. [42] studied pollen fertility of 50 medicinal plants of Shogran Valley. Fertility ratio of the plants ranged from $98 \%-100 \%$, which indicated that flora of Shogran was well established and stable. In the present study among the 3 species of Hypericum; pollen fertility percentage ranged from $82.66 \%$ to $90.90 \%$. It indicates that Hypericum species from Kaghan valley is well established and the species are stable in the area.

\section{Discussion}

In recent studies on palynology of Hyperium by Otaghvari et al., Martonfi et al. and Ocak, et al. [6] [22] [24] the regular and irregular pollen grains have been discussed. In the present study pollen examination of selected Hypericum taxa was conducted from Pakistan for the first time. Interesting findings were found regarding pollen characters of selected species. The pollen fertility estimation of the species was also investigated. Generally pollen grains were small, monad and isopolar. The type of pollen grains $3-4$ colporate in $H$. elodeoides while 3 -colporate in other two species. In polar view in all species pollen shape was circular to semi-angular (Figure 2(a), Figure 2(c) and Figure 2(e)). But in equatorial view the pollen grains were oblate-spherioidal in $H$. elodeoides and $H$. oblongifolium but prolate $H$. perforatum (Figure 2(b), Figure 2(d) and Figure $2(\mathrm{f})$ ). The present study showed palynological variation among these three species of Hypericum especially in exine sculpturing of pollen grain which was foveolate sculpturing in Hypericum elodeoides, reticulate in H. oblongifolium and scabrate in $H$. perforatum. Some of our findings regarding shapes and small to medium size of pollen grains are in accordance with [6] pollen grains but in contrast with regard of exine sculpturing which is different in all species studied. Similarly palynologiacal analysis of seven Hypericum taxa were studied by [31], by light and scanning electron microscopy. According to them there were no essential differences in the exine structure of seven Hypericum species. The 
present showed much variation in regard of pollen shape in equatorial view and sculpturing pattern of exine which was different in all species studied. Pollen grains are mainly classified on the basis of their shape, size, aperture, polarity, symmetry and exine sculpturing. Along with these characters; exine sculpturing pattern is of great importance from phylogenetic and evolutionary point of view [39]. The present study showed that the studied palynological characters would be more useful for further palynological, karyological and taxonomic studies of Hyperium species.

\section{Acknowledgements}

We are thankful to PCSIR Karachi for financial support for SEM and to Centralized Science Laboratory (CSL), University of Karachi for assistance in Scanning electron microscopy. We are also grateful to Department of Plant Sciences, Faculty of Biological Sciences Quaid-i-Azam University Islamabad.

\section{References}

[1] Crockett, S.L. and Robson, N.K.B. (2011) Taxonomy and Chemotaxonomy of the Genus Hypericum. Medicinal and Aromatic Plant Science and Biotechnology, 5, $1-13$.

[2] Crockett, S.L. (2010) Essential Oil and Volatile Components of the Genus Hypericum (Hypericaceae) Natural Product Communications, 5, 1493-1506.

[3] Scotland, R.W. (2000) Taxic Homology and Three-Taxon Statement Analysis. Systematic Biology, 49, 480-500. https://doi.org/10.1080/10635159950127358

[4] APG III (2009) An Update of the Angiosperm Phylogeny Group Classification for the Orders and Families of Flowering Plants.

[5] Ernst, E. (1995) St. John's Wort, an Anti-Depressant? A Systematic, Criteria-Based Review. Phytomedicine, 2, 67-71. https://doi.org/10.1016/S0944-7113(11)80051-6

[6] Otaghvari, A.M., Omrani, K.A. and Fasaei, F. (2015) The Pollen Morphology Study on Some Species of Hypericum L. Genus in the Northern Iran. International Journal of Biology, Pharmacy and Allied Science, 4, 957-967.

[7] Matzk, F., Meister, A., Brutovska, R. and Schubert, I. (2001) Reconstruction of Reproductive Diversity in Hypericum perforatum L. Opens Novel Strategies to Manage Apomixis. The Plant Journal, 26, 275-282.

https://doi.org/10.1046/j.1365-313X.2001.01026.x

[8] Barnes, J., Anderson, L.A. and Phillip, J.D. (2001) St John's Wort (Hypericum perforatum L.): A Review of Its Chemistry, Pharmacology and Clinical Properties. Journal of Pharmacy and Pharmacology, 53, 583-600. https://doi.org/10.1211/0022357011775910

[9] Awan, M.R., Iqbal, Z., Muqarab S., Jamal, Z.S., Jan G., Afzal, M., Majid, A. and Gul, A. (2011) Studies on Traditional Knowledge of Economically Important Plants of Kaghan Valley, Mansehra District, Pakistan. Journal of Medicinal Plants Research, 5, 3958-3967.

[10] Nurk, N.M. and Blattner, F.R. (2010) Cladistic Analysis of Morphological Characters in Hypericum (Hypericaceae). Taxon, 59, 1495-1507.

[11] Nurk, N.M. and Crockett, S.L. (2011) Morphological and Phytochemical Diversity among Hypericum Species of the Mediterranean Basin. Medicinal and Aromatic 
Plant Science and Biotechnology, 5, 14-28.

[12] Ruhfel, B.R., Bittrich, V., Bove, C.P., Gustafsson, M.H.G., Philbrick, C.T., Rutishauser, R., Xi, Z. and Davis, C.C. (2011) Phylogeny of the Clusioid Clade (Malpighiales): Evidence from the Plastid and Mitochondrial Genomes. American Journal of Botany, 98, 306-325. https://doi.org/10.3732/ajb.1000354

[13] Khan, A.H. (1969) Pollen Morphology of Indian Hypericaceae. Palynology, 5, 97-99.

[14] Thomas, J.L. (1970) Haploid and Diploid Pollen in Hypericum patulum. Journal of Arnold Arboratum, 51, 247-250.

[15] Aytug, B., Aykut, S., Merev, N. and Edis, G. (1971) Pollen Atlas of Plants in and around Istanbul. University of Istanbul, No. 1650, Fac For No:174.

[16] Charpin, J., Surinyach, R. and Frankland, A.W. (1974) Atlas of European Allergenic Pollens. Journal of Linnaean Society, 161, 105-121.

[17] Yi, X.-Z. (1979) Pollen Morphology of Guttiferae in China. Acta Botanica Sinica, 21, 36-41. (In Chinese)

[18] Clarke, G.C.S. (1975) Irregular Pollen Grains in Some Hypericum Species. Grana, 15, 117-125. https://doi.org/10.1080/00173134.1975.11864626

[19] Clarke, G.C.S. (1976) The Northwest European Pollen Flora, 7 Guttiferae. Review of Paleobotany and Palynology, 21, 125-142. https://doi.org/10.1016/0034-6667(76)90051-8

[20] Clarke, G.C.S. (1981) Pollen Morphology. pp. 115-118. In: Robson, N.K.B., Ed., Studies in the Genus Hypericum L. (Guttiferae). 2. Characters of the Genus. Bulletin of the British Museum of Natural History (Botany), 8: 55-226.

[21] Barros, M. and Ramos, A. (1984) Study of the Pollen of the Species of Hypericum sect. Hirtella Stef. in the Iberian Peninsula and the Balearic Islands. 5 th Symposium of Palynology. APLE. Abstracts (Cordoba Estudio del polen de lasespecies de Hypericum sect. HirtellaStef. en la Península Ibérica y Baleares. V Simposio de Palinología. APLE. Resúmenes. Córdoba).

[22] Martonfi, P., Janikova, M. and Zezula, I. (2002) Palynological Analysis of Seven Hypericum Taxa. Biologia, Bratisalva, 571, 455-460.

[23] Meseguer, A.S. and Sanmartín, I. (2012) Paleobiology of the Genus Hypericum (Hypericaceae): A Survey of the Fossil Record and Its Palaeogeographic Implications. Anales del Jardin Botanico de Madrid, 69, 97-106.

[24] Ocak, A., Erkara, P.I., Koyuncu, O., Osoydan, K., Yaylaci, O.K., Özgişii, K. and Kurt, F. (2013) Palynological Investigations on Some Hypericum taxa (Hypericaceae) Growing Naturally in Turkey. Plant Systematics and Evolution, 299, 379-388. https://doi.org/10.1007/s00606-012-0728-Z

[25] Jan, S., Khan, M.A., Din, S., Murad, W., Hussain, M. and Ghani, A. (2008) Herbal Remedies Used for Gastrointestinal Disorders in Kaghan Valley, NWFP, Pakistan. Pakistan Journal of Weed Science Research, 14, 169-200.

[26] Raziq, N., Naveed, M., Chishti, K.A., Saeed, M., Rahman, S. and Khan, H. (2011) Correlation of the Antioxidant Capacity with the Phenolic Contents of Hypericummonogynum and Hypericum perforatum. African Journal of Pharmacy and Pharmacology, 5, 1872-1876.

[27] Meo, A.A. (2005) Palynological Studies of Selected Genera of the Tribes of Asteraceae from Pakistan. Ph.D. Thesis, Quaid i Azam University, Islamabad, Pakistan.

[28] Nair, P.K. (1964) Advances in Palynology. National Botanical Garden, Lukhnow. 
[29] Bashir, S. and Khan, M.A. (2003) Pollen Morphology as an Aid to the Identification of Medicinal Plants: Trianthema portulacastrum L., Boerhaaviaprocumbens Banks ex Roxb., and Alternanthera pungens Kunth. Hamdard Medicus, XLVI, 7-9.

[30] Annonymous (1998) District Census Report of Mansehra. Population Census Organization Statistical Division, Government of Pakistan.

[31] Mustafa, G. (2003) An Introduction to Mansehra District. Science-Religion Dialogue. http://www.hssrd.org/journal/spring2003/mansehra.htm

[32] Mazari, P., Khan, M.A., Ali, B., Mangi, J.D., Bux, H, Khan, K.Y., Mughal, S., Ahmad, M., Zafar M. and Akhter, A. (2012a) Palynological Diversity in Selected Medicinal Plant Species of Asteraceae (Compositae) from Flora of Kaghan Valley. Jour nal of Medicinal Plants Research, 6, 2747-2753.

[33] Mazari, P., Khan, M.A., Ahmad, M., Khan, K.Y., Zafar M., Ali, B. and Niamat, R. (2012b) Pollen Fertility Estimation of Selected Taxa of Kaghan Valley, Pakistan. Research in Plant Biology, 2, 16-21.

[34] Erdtman, G. (1952) Pollen Morphology and Plant Taxonomy. Angiosperms. Chron. Bot. Co., Waltham.

[35] Erdtmann, G. (1954) An Introduction to Pollen Analysis. Chron. Bot. Co., Waltham.

[36] Kremp, G.O.W. (1965) Encyclopedia of Pollen Morphology. The University of Arizona Press, Tuscon.

[37] Faegri, K. and Iversen, J. (1964) Text book of Pollen Analysis. 2nd Edition, Muksgaard, Copenhangen.

[38] Punt, W., Hoen, P.P., Blackmore, S., Nilsson, S. and Thomas, A.L. (2007) Glossary of Pollen and Spore Terminology. Review of Palaeobotany and Palynology, 143, 1-81. https://doi.org/10.1016/j.revpalbo.2006.06.008

[39] Walker, J.W. and Doyle, J.A. (1975) The Bases of Angiosperm Phylogeny: Palynology. Annals of the Missouri Botanical Garden, 62, 664-723. https://doi.org/10.2307/2395271

[40] Lawrence, G.H.M. (1969) Taxonomy of Vascular Plants. MacMillan Co., New York, 737-775.

[41] Daiz, Z.I. and Lifante, Z.D. (1991) Asphodelus cirerae, a Forgotten Species of Aspholdelus sect. Verinea (Liliaceae), Morphological, Palynological, Karyological and Ecogeographical Characterization. Flora Mediterrabea, 71, 87-109.

[42] Matin, A., Khan, M.A., Aasraf, M. and Qureshi, R.A. (2002) Pollen Fertility Investigation of the Himalayan Region of Shogran Valley District Mansehra (Hazara), Pakistan. Hamdard Medicus, XLV, 78-81. 